Brit. J. industr. Med., 1956, 13, 196.

\title{
THE USE OF A SIZE SELECTOR FOR DUST SAMPLING WITH THE THERMAL PRECIPITATOR
}

\author{
BY \\ J. T. BURDEKIN and J. G. DAWES \\ From the Safety in Mines Research Establishment, Ministry of Fuel and Power, Sheffield
}

(RECEIVED FOR PUBLICATION NOVEMBER 16, 1954)

Ideally, in order to relate dust concentrations expressed in terms of one parameter, e.g., number per unit volume, with those expressed in terms of another parameter, e.g., mass per unit volume, the particles counted by microscope in a thermal precipitator sample should be within the same size range as samples collected by other means for the determination of mass concentration.

It is generally agreed that dust particles in order to produce pneumoconiosis must usually be less than $5 \mu$ in size, that is to say, that their terminal velocities must be less than that of a sphere of unit density and diameter $5 \mu$. For gravimetric determinations of such dust particles, the sampling instrument is now usually fitted with a size selector, working on aerodynamic principles, designed to have a collecting efficiency of $50 \%$ for $5 \mu$ particles. (It is, of course, not possible to make a size selector with a sharp cut-off at these small sizes.) Existing practice, on the other hand, involves microscopic counting with the aid of a graticule and makes an arbitrary $100 \%$ cut-off visually at a mean cross-sectional diameter of $5 \mu$. This may or may not be almost identical in its outcome with the result obtained with a terminal velocity cut-off.
An investigation has been carried out to compare counts of particles, 1 to $5 \mu$ in diameter, obtained by normal thermal precipitator practice with those obtained when a suitable size selector was fitted to the instrument and counts were made of all particles greater than $1 \mu$ in diameter.

\section{Sampling Procedure}

The size selector used (Fig. 2) was that developed for use with the thermal precipitator by the National Coal Board Central Research Establishment (Hamilton and Walton, 1952). When the sampling rate is $7 \mathrm{cu} . \mathrm{cm} . / \mathrm{min}$. this selector has the characteristic shown in Fig. 1. It can be attached to the top of a thermal precipitator head by means of the gauze filter cap after the gauze screen has been removed. When the selector is in position the face with two slots is uppermost and the slots are parallel

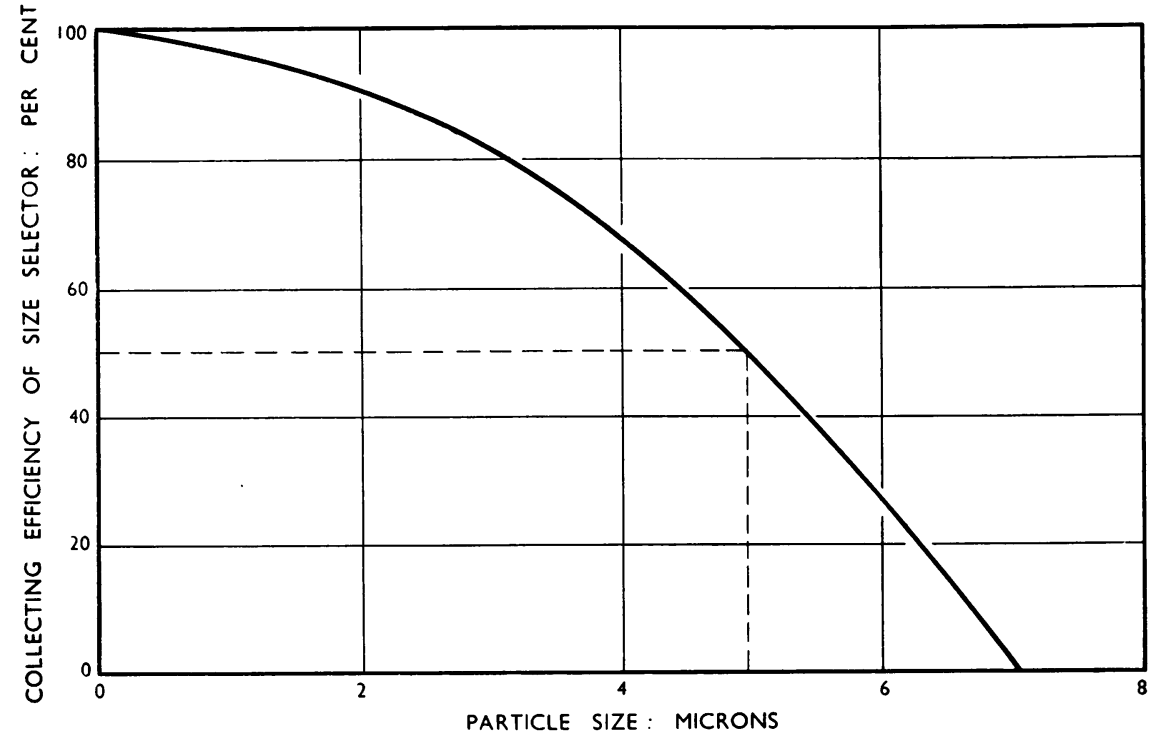

FIG. 1.-Collecting characteristic of size selector. [Crown copyright S.M.R.E. 196 


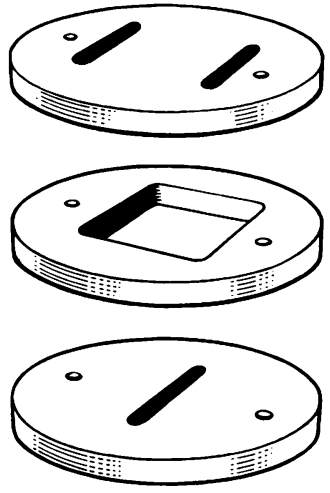

(a) COMPONENT PARTS

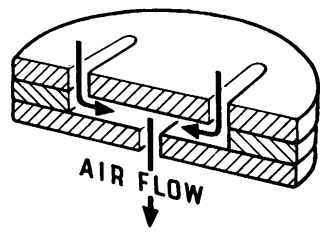

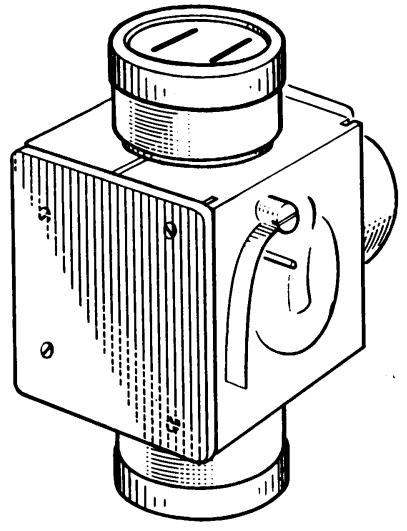

(b) MOUNTED ON T.P. HEAD

FIG. 2.-Size selector for thermal precipitator. [Crown copyright S.M.R.E.

1 to $5 \mu$ diameter in corresponding samples taken with a standard thermal precipitator, and $(b)$ to compare the size distributions in the corresponding pairs of samples in the size ranges 0.5 to 1,1 to $2 \cdot 5,2 \cdot 5$ to 5,5 to 10 , and 10 to $25 \mu$.

In these evaluations, aggregates of particles were counted as one particle where they could not visually be divided into two or more separate entities. This is now the generally accepted procedure.

\section{Discussion of Results}

Lack of space precludes the reproduction of all the results either in tabular form or as curves and diagrams.* Some typical diagrams are given to illustrate the general conclusions.

Two forms of elementary analysis were formed on the data collected.

(1) The ratio was obtained, for each pair of samples, of the number of particles per cc. in the size range greater than $1 \mu$ as measured

with the channel giving entry to the head of the thermal precipitator.

With this device attached to one thermal precipitator only, simultaneous samples were taken (at the rate of $7 \mathrm{cu} . \mathrm{cm} . / \mathrm{min}$.) with two thermal precipitators in a number of different environments in coal-mines throughout the country. As many pairs of samples as possible were taken during a working shift, up to a maximum of 15 pairs; in no case was the number of pairs less than five. In addition, when the main sampling site was on the working face, a similar number of pairs of samples was taken 10 yards down the return airway. During sampling the size selector was changed from one precipitator to the other for alternate samples, and after every second sample the positions of the two thermal precipitators were exchanged.

\section{Environments Sampled}

Sampling was carried out in all the different coalfields in Great Britain during a variety of different mining operations, including the cutting of coal, the getting of coal by pneumatic picks, hand-filling operations, cutterloading operations, belt-loading operations, and drilling operations in a hard heading. In this way, most of the dust-producing operations encountered in coal-mines were investigated and whatever differences there might be in the size distribution of dust clouds so produced would be taken into account.

\section{Evaluation of Samples}

The samples were counted and sized so as (a) to compare the total counts of all particles greater than $1 \mu$ diameter in those samples taken by a thermal precipitator fitted with a size selector with the counts of particles by the thermal precipitator fitted with a size selector to the number of particles per cc. in the size range 1 to $5 \mu$ as measured by the standard thermal precipitator. When the distributions of this ratio for the different sampling positions were compared there was no significant difference between them (see Appendix). This negative result may, to some extent, be due to the statistically small size of the sample of the distribution of the ratio for a given sampling position, but it implies that the distributions may legitimately be combined where they were obtained at sampling positions of like kind.

The combined distribution for different types of sampling situations is shown in Fig. 3. As is not unexpected, the distribution is approximately log normal. It indicates that the mean value of the ratio is of the order unity. If any bias exists it is such as to suggest that the ratio is greater than unity rather than less.

It is clearly desirable to have an estimate of the experimental error so that the dispersion of the values of the ratio shown in Fig. 3 can be examined critically. Ideally, such an estimate would have been obtained by comparing two standard thermal precipitators (neither being fitted with a size selector) in the same clouds as those sampled in the investigation. However, to limit the labour involved in the

* The full tables are available upon request to the authors at the Safety in Mines Research Establishment, Portobello Street, Sheffield, 1. 


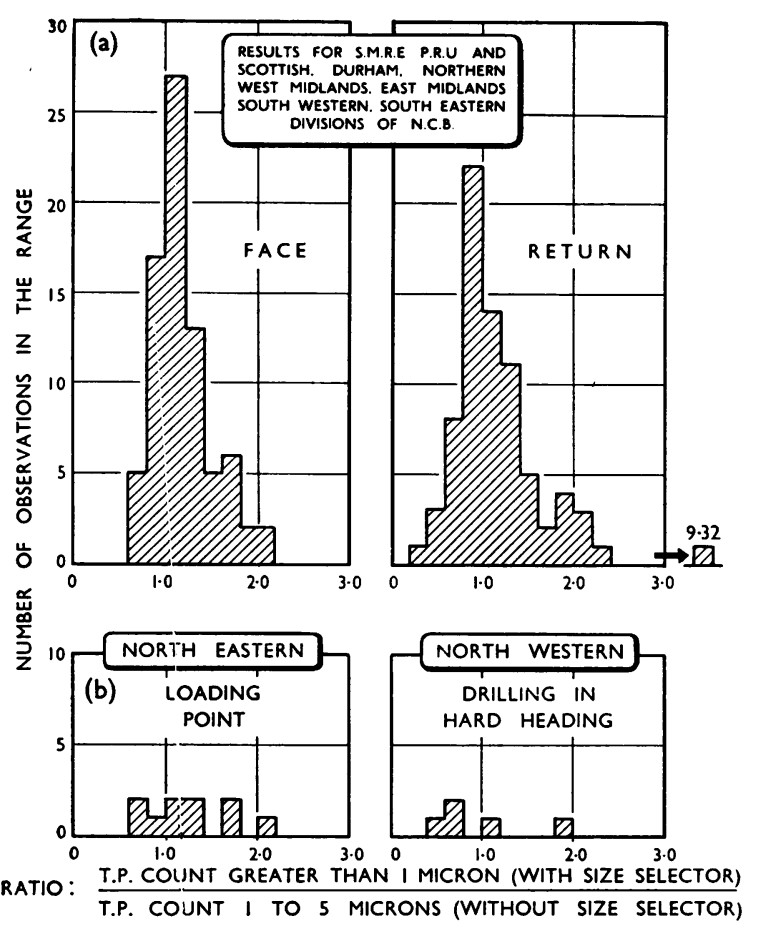

Fig. 3.-Ratio of thermal precipitator counts with and without size selector. [Crown copyright, S.M.R.E.

trial itself, this was not done, so that directly comparable data are not available; but an estimate of the order of magnitude of the experimental error can be obtained from previous work by the Safety in Mines Research Establishment on surveys in return roadways during filling shifts. Fig. 4 shows a histogram obtained from the results of this work by plotting the ratio of the concentrations as measured by two standard thermal precipitators when sampling the same cloud simultaneously. It is seen that the dispersal of the values of the ratio shown in Fig. 4 is similar to that given in Fig. 3. This strengthens the view, therefore, that on the average, due allowance having now been made for experimental error, the count in the size range greater than $1 \mu$ obtained from a thermal precipitator fitted with a size selector is equal to, or somewhat greater than, the conventional count (in the size range 1 to $5 \mu$ ) taken with an ordinary thermal precipitator.

(2) The alternative method of testing the equivalence of the two counts is to examine the regression zones established by plotting the counts one against the other. Typical scatter diagrams are shown in Fig. 5. There are two main types. The first type (Fig. 5a) shows the observations to be evenly scattered about the line of perfect agreement, and is typical of the data obtained by four N.C.B. divisions and by the Pneumoconiosis Research Unit. With the second type (Fig. 5b), the indication is that the values of the count greater than $1 \mu$ with the thermal precipitator fitted with a size selector are somewhat greater than the counts 1 to $5 \mu$ obtained with the standard thermal precipitator. When the ratio was somewhat greater than unity, the samples were taken in clouds of higher concentration. Fig. $5 \mathrm{~b}$ is typical of results obtained by three N.C.B. divisions and by the Safety in Mines Research Establishment. In addition, a third type of scatter diagram was obtained from data presented by two other N.C.B. divisions in which the observations, like those in Fig. 5a, are relatively evenly distributed about the line of perfect agreement; but they are few in number, the range of concentrations sampled is low and, in general, the dust concentrations themselves were low. To help in the assessment of the scatter diagrams, the previously mentioned data, obtained with two standard thermal precipitators sampling the same cloud simultaneously, are plotted in Fig. 6. This illustrates the

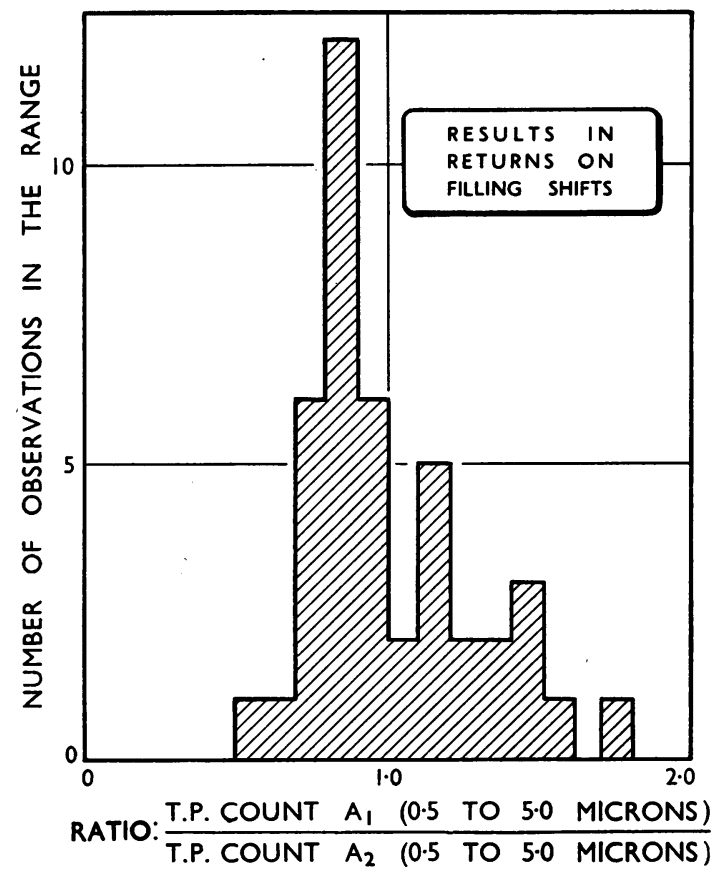

FIG. 4.-Ratio of counts with two standard thermal precipitators. [Crown copyright, S.M.R.E. 


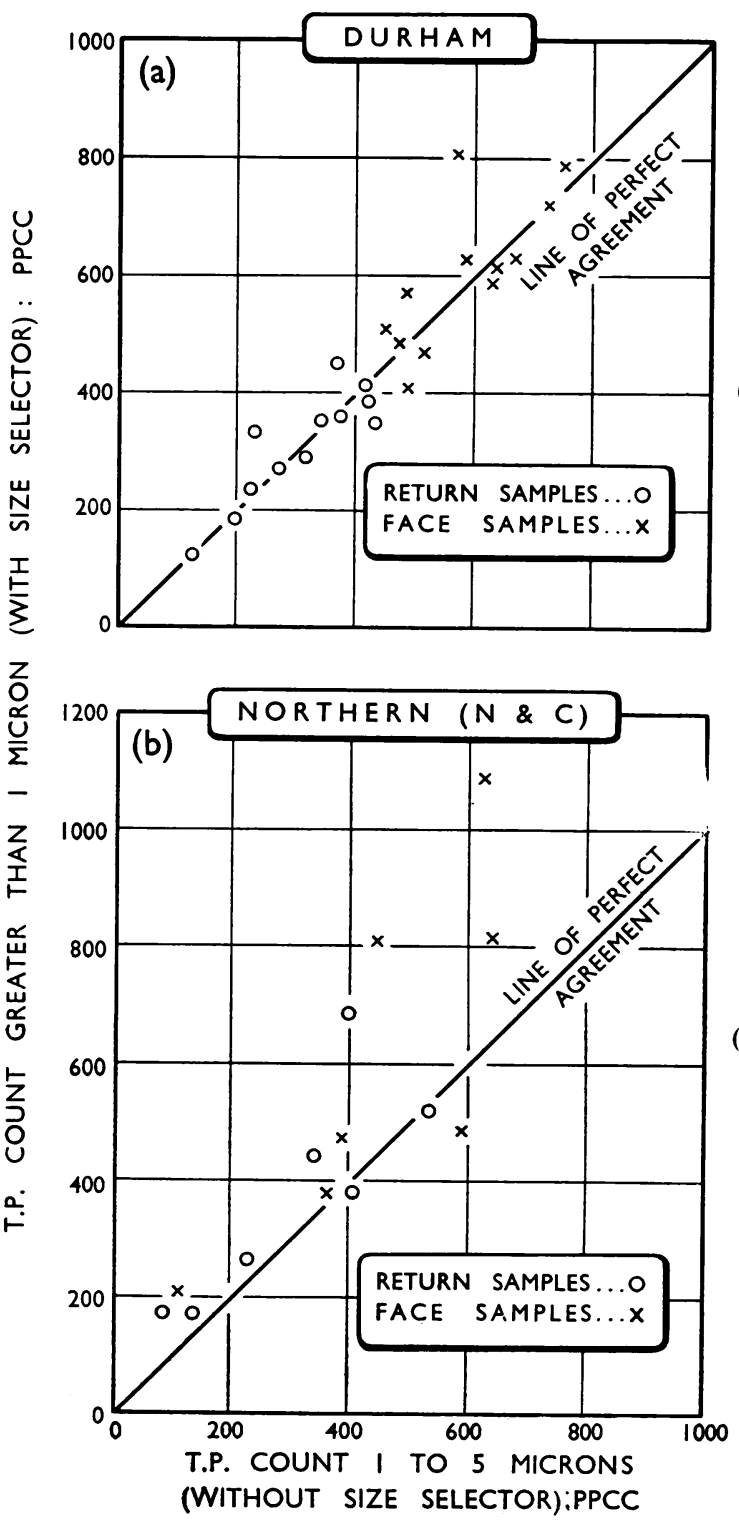

FIG. 5.-Typical examples of relationships between counts with and without size selector. [Crown copyright, S.M.R.E.

magnitude of the experimental errors to be expected in this type of investigation.

Comparison of Fig. 5a and Fig. 6 suggests that there is no reason to suppose that the scatter of the observations about the line of perfect agreement for the Durham data is due to other than experimental error (see also Appendix). This was also the case for the data received from the Pneumoconiosis Research Unit and from five other N.C.B. divisions.

The bias shown in Fig. $5 \mathrm{~b}$ is not readily explained. The count of particles greater than $1 \mu$ from a thermal precipitator fitted with a size selector is larger than the count 1 to $5 \mu$ from the standard thermal precipitator. In all the cases typified by Fig. 5b (there were four other cases) sampling had taken place in high concentrations and the bias may be due to the behaviour of the size selector when it is called upon to eliminate large numbers of coarse particles. When the size selection characteristics of the horizontal elutriator system were determined for each pair of samples, it was noted that in two of the N.C.B. divisions giving scatter diagrams like Fig. 5b, namely Scotland and South Wales, the size selection characteristics were anomalous. Both the face and return samples from South Wales showed a negligible size selection effect as did the face samples in Scotland, though the characteristics for the return samples from Scotland were normal. This effect may be caused by the presence of a large quantity of coarse airborne dust, though the phenomenon needs further investigation.

To summarize the discussion, the results displayed in Fig. 3 and typified by Fig. 5, suggest that there is equivalence within experimental error between the

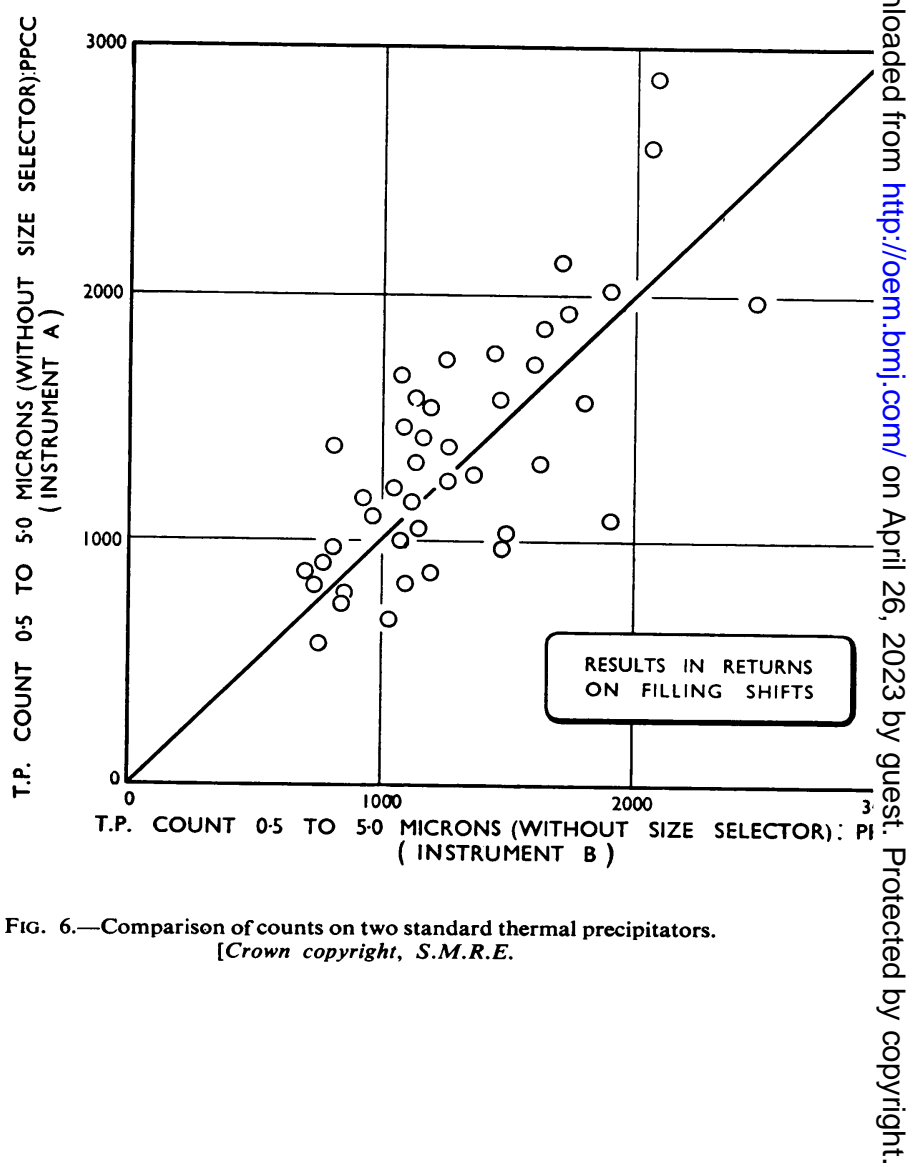


count in the size range 1 to $5 \mu$ from a standard thermal precipitator and the count in the range greater than $1 \mu$ from a sample taken through a size selector of the type tested. There were some exceptions, all similar to one another, which showed a larger count (in the range greater than $1 \mu$ ) when the size selector was used than was obtained by the conventional method without a size selector in the size range 1 to $5 \mu$. The exceptional results may possibly be accounted for by the fact that in these instances heavy concentrations were being sampled with the result that the size selectors tended to become choked with coarse dust.

Thus, while it is more satisfying theoretically if a sampling instrument reproduces the size selection characteristic of the human lung, the results already discussed suggest that the use of a size selector is not essential in sampling with a thermal precipitator. The counts obtained in the normal way for the particles 1 to $5 \mu$ in size were equivalent to those in the size range greater than $1 \mu$ when a size selector is used.

Nor, in the main, did the investigators taking part find that the process of counting had been made easier by the use of the size selector, for seven out of 10 of those who evaluated the samples said that it was not. One investigator stated that although counting was made easier, this facility did not outweigh the disadvantage caused by having to clean the selector between successive samples. This may be necessary if low-pressure constant-head aspirators of the type developed at the Safety in Mines Research Establishment (Dawes, Howarth, and Slack, 1954) come into use. However, with minor modifications, it is possible to increase the capacity of the size selector, for example, by providing a small recess in the bottom plate beneath the entrance channels, and this may avoid the necessity for repeated cleaning.

At first sight, the fact that counting was not made easier when the selector was used appears to be an unexpected finding. The reason may be that most of the difficulty in size determination is met at the lower sizes and in this investigation discrimination had to be made between particles above and below $1 \mu$ in size whether the selector had been used or not. At the top end of the size scale $(5 \mu)$ the difficulty of discrimination would not be so great because of the increased size of the particle in view and also because the number of particles over that size would be relatively small, even in samples taken without the use of the selector.

All these several points, coupled with the fact that the use of the selector causes a loss of information about the size distribution in the range up to
$10 \mu$, suggest that for ordinary purposes there is no advantage to be gained by fitting a size selector. On the other hand, its use would almost certainly facilitate the evaluation of samples by automatic machines, because some of the discrimination between particles carried out by such machines will already have been made by the selector.

The use of a size selector might also have two other possible advantages: it should enable sampling to proceed for longer periods in clouds with many coarse particles without particles on the sample overlapping; it should also reduce the interference caused when large particles adhere to the hot wire.

\section{Summary}

The experiments described in this report were necessary in order to increase our knowledge of the parameter of dust concentration actually measured when airborne dust clouds are sampled by the standard thermal precipitator. It was not known to what extent this parameter was related to the aerodynamic or lung-penetrating properties of the dust particles. An estimate of this relationship has been obtained by the use of a size selector, working on aerodynamic principles, in conjunction with one thermal precipitator, and comparing the results so obtained with those given by an unmodified thermal precipitator.

The results have shown that the present count in the size range 1 to $5 \mu$ with a standard thermal precipitator is a satisfactory measure of the dustcloud concentration; it is not significantly different from the theoretically more satisfying convention of the count greater than $1 \mu$ obtained with a thermal precipitator fitted with a size selector.

In consequence, and in the absence of other substantial advantages, it is not considered desirable to recommend that the size selector should always be used in a thermal precipitator sampling in airborne clouds in British coal-mines.

The work was carried out on behalf of Panel I of the Sub-Committee on Dust, a sub-committee of the Medical Research Council's Committee on Industrial Pulmonary Diseases. The authors' thanks are due to the SubCommittee and to the Ministry of Fuel and Power for permission to publish this paper. Valuable assistance in the arrangements for the underground experimental work was given by Mr. W. H. Walton and Mr. F. Henley Price of the National Coal Board Scientific Staff and by Mr. S. Roach of the Pneumoconiosis Research Unit of the Medical Research Council.

Thanks are also due to the many individuals who carried out the sampling in mines throughout the country and to those who evaluated the samples. 


\section{A P P E N D I X}

The data obtained in any given category were relatively sparse. It was not profitable therefore to carry out statistical tests aimed at great precision. It was, however, worth while to establish that there was no evidence in the data which suggested that it was not legitimate to amalgamate the data from different sampling positions of a given type. Thus, when the distributions of the ratio of the count with the size selector to the count when the size selector was not used at the different sampling positions were compared by the Student $t$ test, there was no indication at the $5 \%$ significance level that the distributions were samples from different populations. Accordingly, the data were combined as shown in Fig. 3 and the resulting distributions may be taken as representative of the overall populations of the ratio at the different types of sampling position. There is no significant difference between the populations of the ratio obtained at the different sampling positions. The data given in Fig. 4 are not strictly comparable with the present results (see also below), because the two standard thermal precipitators were sampling in clouds different from those used in the size selector tests, and also because the counts in the size range 0.5 to $5 \mu$ (instead of 1 to $5 \mu$ ) were recorded. Nevertheless, the data can be used to estimate the order of magnitude of the "experimental" error. When the distributions of Fig. 3 and Fig. 4 are compared, the distributions are found to be not significantly different at the $5 \%$ level.

Again, although the data are not strictly comparable, it is instructive to compare the correlation of the observations of the count with the size selector to the count (in the restricted range 1 to $5 \mu$ ) when no size selector was fitted for the samples from the Durham and Northern (N. \& C.) Divisions with the correlation between the results given by two thermal precipitators when neither is fitted with a size selector and they are sampling simultaneously.

For this purpose, since inspection of Figs. 5 and 6 suggests that the scatter of observations is proportional to the level of the dust-cloud concentrations, the data were transformed logarithmically. As a result the regression zone obtained with the transformed variables become, in effect, constant in width, and a linear regression analysis was carried out. In Table $1, \sigma_{1}$ is the residual standard deviation of the scatter (obtained with the transformed variable) when, for the size selector trials, the count without the selector was taken as the independent variable, and $\sigma_{2}$ the residual standard deviation when the count with the size selector was taken as the independent variable. In the experiments with two standard thermal precipitators, $\sigma_{1}$ and $\sigma_{2}$ were obtained by considering the count first from one thermal precipitator and then from the other as the independent variable.

\begin{tabular}{|c|c|c|c|c|c|}
\hline \multirow[t]{2}{*}{$\begin{array}{c}\text { Origin of } \\
\text { Data }\end{array}$} & \multirow[t]{2}{*}{ Comparison } & \multirow[t]{2}{*}{$\begin{array}{l}\text { Number of } \\
\text { Pairs of } \\
\text { Observa- } \\
\text { tions }\end{array}$} & \multirow[t]{2}{*}{$\begin{array}{c}\text { Correla- } \\
\text { tion } \\
\text { Coeffi- } \\
\text { cients }\end{array}$} & \multicolumn{2}{|c|}{$\begin{array}{c}\text { Residual Standard } \\
\text { Deviation about } \\
\text { Regression Line } \\
\text { (logarithmic } \\
\text { units) }\end{array}$} \\
\hline & & & & $\sigma_{1}$ & $\sigma_{2}$ \\
\hline $\begin{array}{l}\text { S.M.R.E. } \\
\text { Fig. } 6\end{array}$ & $\begin{array}{l}\text { Two stand- } \\
\text { ard thermal } \\
\text { precipitators }\end{array}$ & 42 & $0 \cdot 73$ & 0.095 & $0 \cdot 110$ \\
\hline $\begin{array}{l}\text { Durham } \\
\text { Division } \\
\text { Fig. 5a }\end{array}$ & $\begin{array}{l}\text { Thermal } \\
\text { precipitator } \\
\text { with size } \\
\text { selector and } \\
\text { one with no } \\
\text { size selector } \\
\text { fitted }\end{array}$ & 24 & 0.92 & 0.078 & 0.097 \\
\hline $\begin{array}{l}\text { Northern } \\
\text { (N. \& C.) } \\
\text { Division } \\
\text { Fig. 5b }\end{array}$ & do. & 14 & 0.91 & 0.113 & $0 \cdot 120$ \\
\hline
\end{tabular}

On this basis, the scatter of the observations from Durham is somewhat less, while that for the Northern (N. \& C.) Division is somewhat greater than that obtained with thermal precipitators on which size selectors were not fitted. There is no evidence, therefore, that the scatter of the results about the line of perfect agreement, when results with and without the size selector are compared, is due to anything other than experimental error.

\section{REFERENCES}

Hamilton, R. J., and Walton, W. H. (1952). “ The Selective Sampling of Airborne Dust." National Coal Board Scientific Dept. Central Research Establishment Report No. 139.

Dawes, J. G., Howarth, S. R., and Slack, A. (1954). Safety in Mines Research Establishment Research Report No. 87. 